\title{
Proteínas atractantes en orina de hembras Panulirus argus (Latreille, 1804)
}

\author{
Attractant proteins in urine of females Panulirus argus (Latreille, 1804) \\ Oviana Oquendo ${ }^{1}$, Yanis Cruz ${ }^{1}$ y Osmel García ${ }^{1}$ \\ ${ }^{1}$ Centro de Investigaciones Pesqueras, $5^{\text {ta }}$ Avenida y calle 246, Santa Fe, \\ Playa, Ciudad Habana, Cuba C.P. 19100 \\ oviana.cuba@gmail.com
}

\begin{abstract}
Pheromones have been described in decapods, but not in Panulirus argus. To determine these attractants on urine of females $P$. argus 100 females were sampled from fishing areas of Isla de la Juventud, Cuba. Urine was extracted from bladders and subjected to a procedure to extract proteins. The proteins were run in two electrophoresis of polyacrylamide gel. In the first three, noticeable bands were observed. The second
\end{abstract}

electrophoresis corroborated that these bands are subunits of one protein. Sponges soaked with protein material were exposed to individuals, resulting in attractiveness for males. It suggests that these proteins act as sex pheromones.

Key words: Spiny lobsters, electrophoresis, attraction, sex pheromones

\section{Introducción}

Las feromonas en animales acuáticos, como peces y crustáceos, han evolucionado a partir de moléculas que son excretadas en la orina (Wyatt 2003). Autores como Teytaud (1971), Gleeson (1980, 1982), Seifert (1982), Hardege et al. (2002), Atema (1984), Ameyaw-Akumfi \& Hazlett (1975) y Tierney et al. (1984), entre otros apoyan este planteamiento.

De Panulirus argus (Latreille, 1804), a pesar de ser la más importante entre las especies de langostas espinosas (Puga \& de León 2003), aún no se conocen las bases químicas que rigen la atracción. De ahí que el objetivo de este trabajo fue examinar la orina de hembras $P$. argus con el fin de conocer si existe alguna sustancia con características de atractante sexual.

\section{Material y métodos}

Se recolectaron 100 hembras de $P$. argus provenientes de los desembarques al centro de acopio de Punta del

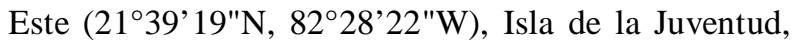
Cuba, en abril 2007. Los animales se extrajeron al azar desde las descargas realizadas por barcos que trabajan en la zona.

La orina se extrajo de cada vejiga por punción con agujas hipodérmicas y jeringas de $5 \mathrm{~mL}$. Se introdujo la aguja hasta su porción media, perforando la membrana artrodial de cada antena y se extrajo la orina por succión. Este método no ha sido descrito previamente en la literatura.

Las muestras de orina fueron almacenadas en frascos
Eppendor $\mathrm{f}^{\circledR} \mathrm{de} 1,5 \mathrm{~mL}$ y conservadas en hielo hasta llegar al laboratorio donde fueron procesadas. Cuando los animales tenían ambas vejigas llenas, los volúmenes obtenidos fueron vaciados en diferentes frascos y rotulados con el número correspondiente al ejemplar. A las hembras ovígeras o con masa espermatófora adherida al abdomen también se les extrajo orina. El procesamiento de las muestras se realizó en el Laboratorio de Sanidad Acuícola, de la División de Inocuidad de los Alimentos y Sanidad del Centro de Investigaciones Pesqueras (CIP).

La orina fue centrifugada a $14.000 \mathrm{rpm}$ durante 10 min en una microcentrífuga Eppendorf ${ }^{\circledR}$. El sobrenadante fue separado y mezclado con solución tampón fosfato salina (PBS), pH 8, en proporción 1:2 y el volumen obtenido fue mezclado con una solución saturada de sulfato de amonio en proporción 1:4 para precipitar las proteínas en caso de en las muestras. Luego de añadir todo el volumen de sulfato de amonio las muestras fueron conservadas a $4^{\circ} \mathrm{C}$ durante $24 \mathrm{~h}$ para facilitar la precipitación. En las muestras donde se obtuvieron precipitados, el volumen se centrifugó nuevamente a $14.000 \mathrm{rpm}$ durante $10 \mathrm{~min}$. El sobrenadante se eliminó y el precipitado se diluyó nuevamente en solución PBS. A continuación las muestras fueron dializadas durante 24 h contra solución PBS a $5^{\circ} \mathrm{C}$. Posteriormente se realizó el protocolo de preparación de muestras para electroforesis de proteínas en gel de poliacrilamida (SDSPAGE) según Laemmli (1970).

Previo a las corridas electroforéticas las muestras fueron desnaturalizadas a $100^{\circ} \mathrm{C}$ durante $5 \mathrm{~min}$. Las corridas electroforéticas se realizaron a una concentración 
del $15 \%$ del gel. En la primera corrida se utilizó mercaptoetanol como agente reductor para las proteínas y en la segunda, se corrieron tres muestras reducidas con mercaptoetanol y dos en condiciones no reducidas o nativas. El gel de la primera corrida se coloreó con Azul de Coomasiee G-250 y en la segunda fue revelado con nitrato de plata. Las fotografías se tomaron con una cámara digital Nikon ${ }^{\circledR}$ modelo Coolpix 2200.

\section{Prueba de actividad biológica}

La prueba de actividad biológica se llevó a cabo en un estanque de $6 \mathrm{~m}^{3}$ aproximadamente, en el Acuario Nacional de Cuba. En el estanque se encontraban seis hembras y dos machos adultos de $P$. argus, previamente adaptados durante cuatro meses. Los individuos de $P$. argus fueron alimentados antes de iniciar el ensayo.

Para la prueba se utilizaron siete fragmentos cúbicos de esponja y cinco muestras con extractos de proteínas identificadas como 410, 309, 319, 200, 402, provenientes de animales diferentes. Cinco de los siete fragmentos usados en el ensayo fueron inyectados con los extractos. Inmediatamente se interrumpió la entrada de agua y los siete fragmentos fueron sumergidos en el acuario y posicionados siguiendo una línea recta que comenzaba en el extremo cercano a la entrada del agua, con los dos fragmentos sin proteínas; el resto de los fragmentos se dispuso a continuación, tratando de cubrir el ancho del acuario. Cada fragmento se colocó a una distancia aproximada de $25 \mathrm{~cm}$ de los otros por ambos lados. Cuando todos los fragmentos estuvieron sumergidos se abrió la entrada de agua entre 2 y 5 min para dispersar las proteínas embebidas en las esponjas. Pasado este tiempo se cerró el sistema hasta finalizar el ensayo.

Se evaluaron los efectos de la conducta de acercamiento a los fragmentos, la manipulación, la cantidad de esponjas visitadas y si los animales eran estimulados por todas las esponjas o solo por las que contenían proteínas.

\section{Resultados y discusión}

\section{Electroforesis de proteínas}

Las proteínas se hicieron evidentes en 10 muestras de orina de siete ejemplares. En todas las muestras se encontraron las mismas proteínas. La Fig. 1 muestra tres bandas más oscuras que el resto, que corresponden a tres proteínas ó péptidos de bajo peso molecular (PM). La segunda electroforesis (Fig. 2) arrojó que las bandas obtenidas pertenecen a una misma proteína.

En las muestras que fueron reducidas con mercaptoetanol los enlaces disulfuro intracatenarios e intercatenarios son disociados y las subunidades se separan como cadenas peptídicas individuales, es por eso que al correr las proteínas en su forma nativa encontramos en la Fig. 2 que una sola proteína es la que se ha aislado de las muestras de orina y que ésta corre íntegra dejando una sola huella en el carril.

El hecho de que la orina de los crustáceos sea almacenada es un indicador de la necesidad de una liberación controlada. La orina es liberada por los nefroporos, localizados en la base de las antenas y relacionados directamente a la corriente branquial, por lo que se sugiere que esta corriente es utilizada, entre otras funciones, como un sistema para dispersar la señal química; de hecho la corriente branquial llega a proyectar la orina a una distancia de siete veces la longitud del cuerpo del animal (Atema \& Cowan 1986). Después de esta distancia se diluye y las corrientes locales se encargan de disipar y diluir estas señales y no es sino a través de esta estrategia que las feromonas pueden ser detectadas por otros individuos.

\section{Ensayo de actividad biológica}

El ensayo de actividad biológica mostró que las proteínas obtenidas eran solubles en agua, característica necesaria para lograr una rápida difusión y dispersión. Según Hickman et al. (2001) la liberación de feromonas se produce a bajas concentraciones y aún así son detectadas por los órganos olfatorios, ya que el olfato es un sentido capaz de cubrir áreas extensas y las células receptoras olfativas tienen un umbral de sensibilidad muy bajo, alcanzando a detectar cantidades de sustancia por debajo de 1 nanomolar (Derby et al. 1991).

De los ocho ejemplares que se encontraban en el acuario solo los machos fueron estimulados con las fuentes que contenían las proteínas, lo que sugiere su capacidad atractante género-específica. A los pocos minutos de haber cerrado la entrada de agua hacia el estanque los dos machos comenzaron a acercarse a las esponjas impregnadas con las proteínas. Ambos se detenían frente a cada esponja, pasaban sus anténulas sobre ellas y las manipulaban con los pereiópodos y el segundo par de patas. Luego de agarrar cada esponja, la acercaban hacia los maxilípedos y el abdomen y la manipulaban durante varios segundos acercando la fuente estimulante hasta la base de las patas posteriores. Los maxilípedos son apéndices en los cuales se ha descrito la presencia de quimiorreceptores mas relacionados con el sentido del gusto que con el olfato (Derby et al. 2001).

En el caso de las hembras, dos de ellas pasaban con frecuencia caminando por el lado de las esponjas pero no se interesaban por ellas, el resto permaneció sin 


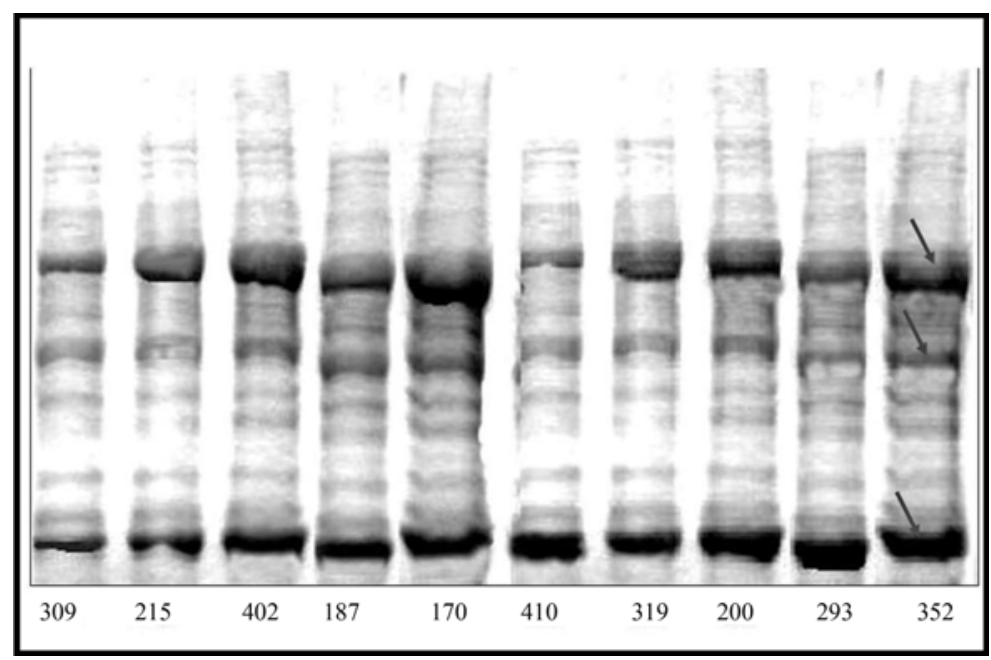

Figura 1

Electroforesis de proteínas provenientes de orina de hembras $P$. argus, en gel de poliacrilamida (SDS-PAGE) al 15\% mostrando tres bandas de mayor concentración (flechas) que se repiten en todos los carriles muestras

Electrophoresis for proteins of urine from P. argus females, in 15\% polyacrylamide gel (SDSPAGE), showing three remarkable bands (arrows) evidenced in all the samples

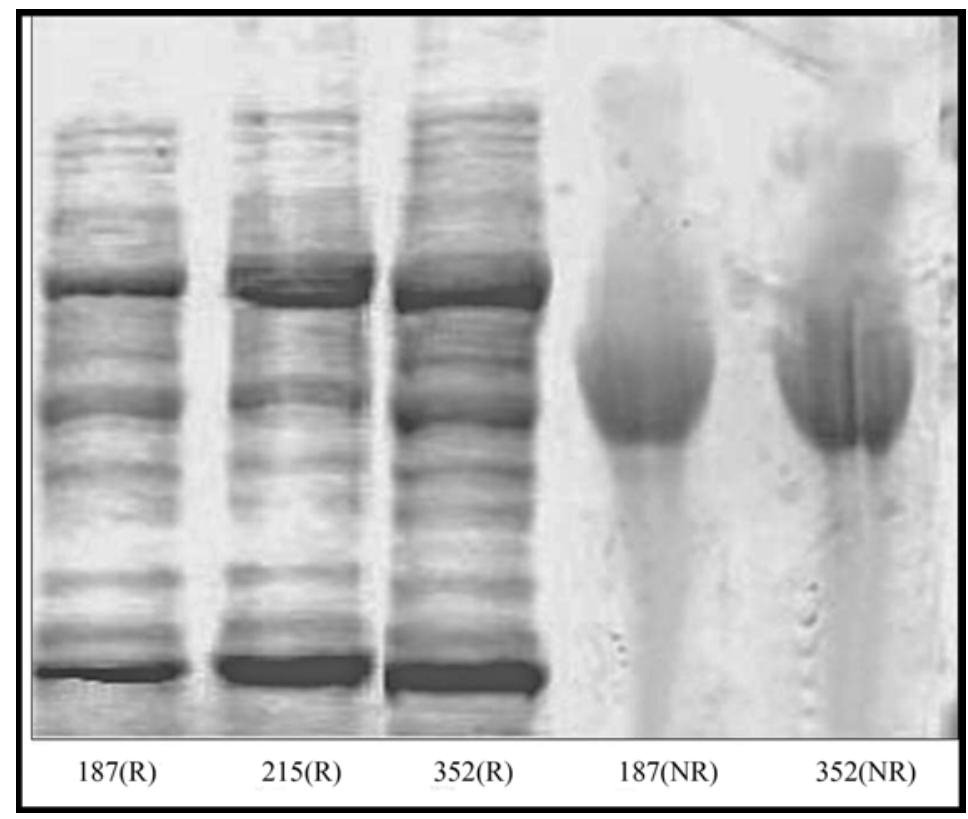

Figura 2

Electroforesis de proteínas provenientes de orina de hembras $P$. argus, en gel de poliacrilamida (SDSPAGE) al 15\% . (R): Proteínas reducidas con mercaptoetanol, (NR): Proteínas no reducidas

Electrophoresis for proteins of urine from P. argus females, in 15\% polyacrylamide gel (SDS-PAGE). (R): Proteins reduced with mercaptoethanol, (NR): Natives proteins 
cambios conductuales aparentes. Según Daloze et al. (1980) no siempre las feromonas promueven una atracción positiva, en efecto, algunas pueden actuar como repelentes frente individuos del mismo sexo. Finalmente, según las observaciones de este experimento podemos sugerir que las proteínas obtenidas pudieran funcionar como feromonas sexuales liberadas por las hembras para atraer a los machos.

\section{Literatura citada}

Ameyaw-Akumfi C \& BA Hazlett. 1975. Sex recognition in crayfish Procambarus clarkii. Science 190: 1225-1226.

Atema J. 1984. Review of sexual selection and chemical communication in the lobster, Homarus americanus. Canadian Journal of Fisheries and Aquatic Sciences 43: 2283-2290.

Atema J \& D Cowan. 1986. Sex-identifying urine and molt signals in lobster (Homarus americanus). Journal of Chemical Ecology 12: 2065-2080.

Daloze D, JC Braekman \& B Tursch. 1980. Chemical communication in the marine environment. En: Gilles R (ed). Animals and environmental fitness: physiological and biochemical aspects of adaptation and ecology 1: 243-261. Pergamon Press, Oxford.

Derby CD, MN Girardot \& PC Daniel. 1991. Responses of olfactory receptor cells of spiny lobsters to binary mixtures. I. Intensity mixture interactions. Journal of Neurophysiology 66: 112-130.

Derby CD, AJ Horner, HS Cate \& P Steullet. 2001. The sensory basis to feeding behavior in the Caribbean spiny lobster Panulirus argus. Marine and Freshwater Research 52: $1339-1350$.

Gleeson RA. 1980. Pheromone communication in the reproductive behaviour of the blue crab, Callinectes sapidus. Marine Behaviour and Physiology 7: 19-134.
Gleeson RA. 1982. Morphological and behavioral identification of the sensory structures mediating pheromone reception in the blue crab Callinectes sapidus. The Biological Bulletin 163: 162-171.

Hardege JD, A Jennings, D Hayden, CT Muller, D Pascore, MG Bentley \& AS Clare. 2002. Novel behavioural assay and partial purification of a female-derived sex pheromone in Carcinus maenas. Marine Ecology Progress Series 244: 179-189.

Hickman CP, LS Roberts \& A Larson. 2001. Integrated principles of zoology, 899 pp. McGraw Hill, Boston.

Laemmli UK. 1970. Cleavage of estructural protein during the assembly of the head of bacterophage T4. Nature 277 : 680-685.

Puga R \& ME de León. 2003. Report of the scientific meeting of the second workshop on the management of the lobster fisheries in the WECAFC Area. En: Report of the Second Workshop on the Management of Caribbean Spiny Lobster Fisheries in the WECAFC Area. FAO Fisheries Report 715: 197-200.

Seifert P. 1982. Studies on the sex pheromone of the shore crab, Carcinus maenas, with special regard to ecdysone excretion. Ophelia 21: 147-158.

Teytaud AR. 1971. The laboratory studies of sex recognition in the blue crab Callinectes sapidus (Rathbun). University of Miami Sea Grant Report 15: 1-63.

Tierney AJ, CS Thompson \& EW Dunham. 1984. Site of pheromone reception in the crayfish Orconectes propinquus (Decapoda, Cambaridae). Journal of Crustacean Biology 4: 554-559.

Wyatt TD. 2003. Pheromones and animal behaviour: communication by smell and taste, $408 \mathrm{pp}$. Cambridge University Press, Cambridge. 